\title{
Island biology and morphological divergence of the Skyros wall lizard Podarcis gaigeae: a combined role for local selection and genetic drift on color morph frequency divergence?
}

\author{
Anna Runemark ${ }^{1 *}$, Bengt Hansson ${ }^{1}$, Panayiotis Pafilis ${ }^{2,3}$, Efstratios D Valakos ${ }^{4}$, Erik I Svensson ${ }^{1}$
}

\begin{abstract}
Background: Patterns of spatial variation in discrete phenotypic traits can be used to draw inferences about the adaptive significance of traits and evolutionary processes, especially when compared to patterns of neutral genetic variation. Population divergence in adaptive traits such as color morphs can be influenced by both local ecology and stochastic factors such as genetic drift or founder events. Here, we use quantitative color measurements of males and females of Skyros wall lizard, Podarcis gaigeae, to demonstrate that this species is polymorphic with respect to throat color, and the morphs form discrete phenotypic clusters with limited overlap between categories. We use divergence in throat color morph frequencies and compare that to neutral genetic variation to infer the evolutionary processes acting on islet- and mainland populations.

Results: Geographically close islet- and mainland populations of the Skyros wall lizard exhibit strong divergence in throat color morph frequencies. Population variation in throat color morph frequencies between islets was higher than that between mainland populations, and the effective population sizes on the islets were small ( $\left.N_{e}: S<100\right)$. Population divergence $\left(F_{S T}\right)$ for throat color morph frequencies fell within the neutral $F_{S T}$-distribution estimated from microsatellite markers, and genetic drift could thus not be rejected as an explanation for the pattern. Moreover, for both comparisons among mainland-mainland population pairs and between mainland-islet population pairs, morph frequency divergence was significantly correlated with neutral divergence, further pointing to some role for genetic drift in divergence also at the phenotypic level of throat color morphs.

Conclusions: Genetic drift could not be rejected as an explanation for the pattern of population divergence in morph frequencies. In spite of an expected stabilising selection, throat color frequencies diverged in the islet populations. These results suggest that there is an interaction between selection and genetic drift causing divergence even at a phenotypic level in these small, subdivided populations.
\end{abstract}

\section{Background}

The role of genetic drift in population divergence and speciation has been a much debated topic in evolutionary biology [1-5]. Early theoretical models of speciation, so-called "peak-shift models", suggested that genetic drift must be a strong force if a population was to move from one adaptive peak to another, and hence cross a valley with lower fitness $[5,6]$. These early models

\footnotetext{
* Correspondence: Anna.Runemark@zooekol.lu.se

'Section for Animal Ecology, Ecology Building, Lund University, SE-223 62 Lund, Sweden

Full list of author information is available at the end of the article
}

generated much controversy and it was later argued that these proposed scenarios were unlikely to be important in population divergence and speciation [1,2]. More recent theoretical models have generated renewed interest for the possibility of genetic drift in speciation. These new models suggest that genetic drift can operate when there exist neutral adaptive ridges in multivariate "holey adaptive landscapes" [3]. Several recent empirical and theoretical studies suggest possible interactions between stochastic factors and selection during evolutionary divergence. For instance, genetic drift can influence population divergence in adaptive phenotypic traits 
during a short and transient period if selection is temporally relaxed [7-10]. Genetic drift has also been suggested to promote speciation, especially when drift interacts with sexual selection [11]. However, empirical evidence for these scenarios is still rather limited, especially the possible interactions between genetic drift and selection. More generally, various forms of stochasticity have been ignored in most evolutionary studies, and it has been pointed out that genetic drift can also take place in large populations [12].

It is an empirical challenge to argue for a role for genetic drift at the level of phenotypes, since most biologists, for good reasons, believe that phenotypic evolution is mainly influenced by the deterministic forces of natural or sexual selection $[13,14]$. One possible approach might be to study whether the population distribution of a heritable phenotypic character differs from the neutral expectation or not $[7,15,16]$. Neutral genetic markers can be used to estimate the effective population sizes $\left(\mathrm{N}_{\mathrm{e}}\right)$, and from such data, the expected probability of fixation of neutral and selected alleles can be calculated. The strength of genetic drift is inversely proportional to $\mathrm{N}_{\mathrm{e}}$ and hence drift is a more important force in small populations [17]. If it can be demonstrated that $\mathrm{N}_{\mathrm{e}}$ is small, the potential for genetic drift would increase, both at the phenotypic and at the molecular levels. It is important to emphasize that stochastic factors such as drift, historical contingencies and the initial genetic makeup of populations, could interact with deterministic factors like selection [18-20]. Thus, the critical issue here is not whether genetic drift and stochastic factors solely influence population divergence of phenotypic traits, but rather if, and to what extent, stochastic factors might interact with deterministic factors such as selection during evolutionary diversification [21].

Discrete and visible color polymorphisms are excellent phenotypic model systems for the study of evolutionary processes in natural settings [22-24]. Past studies of such polymorphisms have addressed some central issues in population genetics and evolutionary biology, ranging from the question of how genetic variation is maintained in natural populations to speciation processes [23-25]. Color is often also genetically and phenotypically correlated to suites of other morphological, physiological and behavioral traits, e.g. testosterone levels, aggression and disease resistance [26-29]. When the genetic basis of such color polymorphisms is known, the theoretical and analytical framework of population genetics can be used to infer the selective causes behind the spatial variation and the temporal dynamics of morph frequencies [22,25]. Moreover, such studies of the morphs can be used in combination with population estimates of neutral or nearly neutral molecular genetic markers $[7,15]$. Such color polymorphisms sometimes seem to have a relatively simple genetic basis (one or a few loci) [22]; as appears to be the case for the sideblotched lizard (Uta stansburiana) where throat color segregates as a single locus (Mendelian) character [30-32] and the Australian Painted dragon (Ctenophorus pictus) where a similar simple inheritance pattern might operate [33]. In the brown Anoline lizard (Anolis sagrei), a two-locus inheritance system with epistatic interactions seems to be involved in the determination of back pattern morphs [34].

Although a genetic background for the throat color polymorphism in lizards is often assumed [30-34], no cross-breeding studies have been done to investigate whether it would be governed by a single locus or multiple loci (but see [33]), and the gene(s) involved has not been mapped at the molecular level. It has also been argued that throat color in Lacerta vivipara [35] is a continuous character, although [36] argues that it is a discrete, mendelian trait. An additional role for phenotypic plasticity, where the same genetic background has different outcomes in different environments [37], can not be excluded. The high heritabilities estimated from some studies [31] indicate that the role of phenotypic plasticity is small in comparison to the genetic component. Although one can certainly raise caveats for some of these previous studies, and a simple genetic basis can be questioned in some cases, it is quite clear that color polymorphisms in lizards are often heritable, making such traits useful model systems in studies of the relative role of genetic drift vs. selection.

Mechanisms that might contribute to maintain color polymorphisms in populations include negative frequency-dependent male-male competition $[26,38]$, negative frequency-dependent male mating harassment [25], female preferences for unfamiliar mates [39-41], selection in spatially and temporally heterogeneous habitats [42] and sexual selection in combination with microhabitat-specific selection [43]. If a selection pressure connected to a well-defined environmental factor operates on such color morphs, the morph frequencies are expected to change in a parallel fashion across similar ecological environments. In contrast, if genetic drift or other stochastic factors are the predominant evolutionary forces acting on the color morphs, then no such parallelism between morph frequencies and environments are expected. On the other hand, if the color morphs are maintained by negative frequency-dependent selection of a similar kind and magnitude across all populations, then at evolutionary equilibrium, morph frequency divergence should be significantly lower than neutral genetic divergence [15]. In contrast, if directional selection acts on the color morphs in a heterogeneous ecological environment, one would expect more 
pronounced population divergence in morph frequencies than expected for the neutral genetic variation $[44,45]$. Finally, under temporally varying selection, genetic drift might partly influence morph frequencies during periods of relaxed selection $[7,9,23]$, which could result in a pattern of morph frequency divergence that would not be discernible from the neutral expectation.

Polymorphic taxa can also shed light on speciation processes; such morphs can serve as starting material for the formation of new species, a process that might be caused by social selection in sympatry $[46,47]$. Two or more morphs can diverge in different directions already in sympatry, and accelerated evolutionary divergence might subsequently follow if one of these initial morphs later becomes fixed by selection or by stochastic factors in a population $[23,43,47]$.

In many lizard species, including the European Podarcis-clade, color polymorphisms are widespread and multiple throat color morphs coexist within populations $[27,48,49]$ (Fig. 1). Here we present the results of a study of the endemic Skyros wall lizard (Podarcis gaigeae) where we study the frequency distribution of throat color morphs in different populations to infer the nature of the selective processes that are acting on the throat color morphs in mainland- and islet populations of this species. This lizard occurs on the island of Skyros in Greece and also on many of the small islets located along the coast of Skyros [48]. The lizard populations on these islets also exhibit substantial morphological inter-islet differentiation, and there are some examples of island gigantism [50]. This biogeographical setting of a large "mainland" area (Skyros) surrounded by smaller islets isolated from the mainland by a few hundred meters of sea is an ideal and classic setting to address issues about the role of stochasticity versus local selection in the divergence of phenotypic traits. In this study, we used molecular (microsatellite) markers to estimate neutral divergence in islet- and mainland populations, and compared the neutral genetic divergence to the divergence in throat color morph frequency. Based on these comparisons we discuss the relative role of genetic drift on morph frequencies in these different geographical settings.

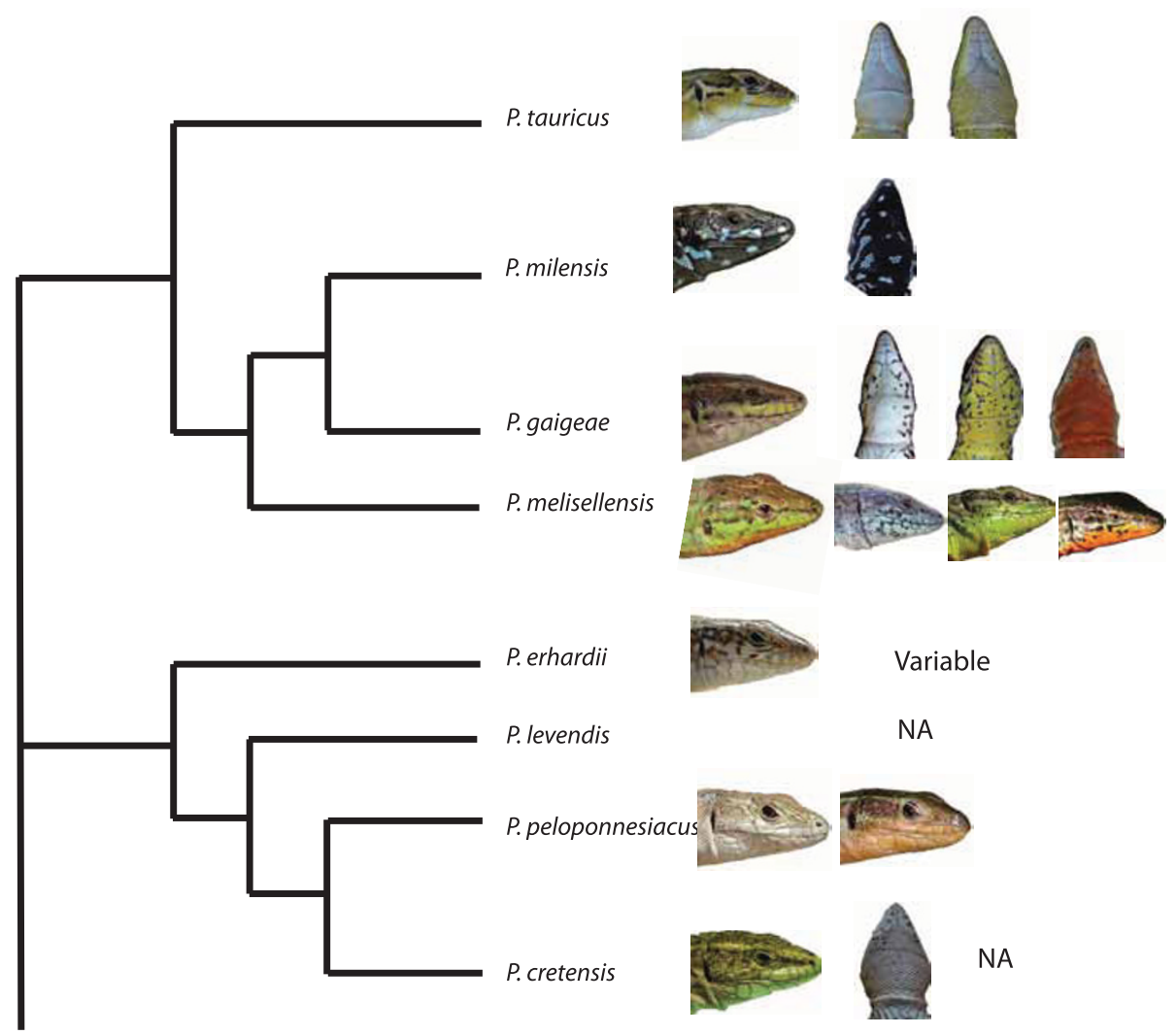

Figure 1 Throat color variation in the Balkan Podarcis-clade. Examples of some of the intra- and interspecific variation in throat color which is found in the Balkan Peninsula group of Podarcis shown on a pruned phylogenetic tree, whose topology was obtained from recent molecular studies $[51,90]$. Note especially the presence of intraspecific throat color polymorphisms in at least two species (P. gaigeae and $P$. mellisilensis) and the entire black throat of the island endemic $P$. milensis on Milos. 


\section{Methods}

Study species, geographical setting and natural history of islands

The Skyros wall lizard $P$. gaigeae is a small bodied insectivorous lacertiid lizard. It is endemic to the Greek island Skyros and its surrounding archipelago [51] with the exception of the subspecies, P. g. weigandi which is found on the island of Piperi [48]. For comparative reasons, this subspecies was also included in this study to compare morph frequencies within P. g. gaigeae between populations on Skyros, the islets surrounding Skyros and the geographically isolated P. g. weigandi. The fragmentation of the landmass which led to the formation of the archipelago of Skyros, and hence the separation from Piperi, had occurred by the early Eemian period [52,53]. Today Piperi is situated 40 kilometers north of Skyros (Fig. 2A). Populations of P. g. gaigeae on small islets close to the coast of Skyros show pronounced morphological differentiation, including at least two cases of island gigantism (A. Runemark and E. I. Svensson, unpublished data). Predation rates on islands are often reduced [54] which is also the case for the islets in the Skyros archipelago [50]. The islets close to the coast of Skyros are known for their highly differentiated floral composition and substantial inter-islet variation, and the patterns show some signals of community drift [55].

\section{Field work and sample collection}

Lizards were caught at eight different geographic localities, hereafter referred to as "populations". P. g. gaigeae was caught at four different "mainland" localities on the island of Skyros and on three islets close to the coast of Skyros. Lizards of the subspecies P. g. weigandi were caught on the island of Piperi (Fig. 2A). Two of the mainland populations and two islet populations were sampled during two consecutive years to ensure that there were no large fluctuations in throat color morph frequency between years. A small part of the tail was collected and immediately preserved it in 99\% ethanol for subsequent DNA extraction. All captured animals were photographed with a DMC FX01 Panasonic color camera in an optical isolated box using the built-in xenon flash. Constant illumination was verified with a white background reference. Specular reflections were avoided with two crossed polarization filters. The sex of the lizards was determined through inspection of the femoral pores which are more developed in males than in females [48]. All animals were released after measurement and samples had been taken and sampling was approved by the Hellenic Herpetological Society and the National Sea Park of Alonissos North Sporades.

\section{Quantitative color analysis of morphs}

The lizards were visually classified to one of six clearly discernible throat color categories ("morphs": orange $(\mathrm{O})$, yellow-orange (YO), orange-white $(\mathrm{OW})$, yellow $(\mathrm{Y})$, yellow-white $(\mathrm{YW})$ or white $(\mathrm{W}))$. All these six phenotypes exhibited either one or a combination of any two of the three colors (orange, yellow and white) present in the system, from inspection of the photographic images. No instances of all three colors on the throat of the same lizard were found. To evaluate the reliability of this discrete visual classification system, another observer (E. I. Svensson) independently re-classified a total of 40 lizards that had previously been classified by A. Runemark. In all but two cases (38 out of 40), the independent classifications were identical. This suggests that these color morphs are easily distinguishable with little ambiguity between different observers, possibly reflecting the discrete nature of these morphs.

To further quantify the discreteness of these color morphs, we analyzed the throat area from the images of the individual lizards and used the data in a more quantitative analysis. A total of 351 lizard throats, 320 P. $g$. gaigeae and 31 P. g. weigandi, were photographed and visually classified to different color morphs from the images. Due to the variance in intensity, which was related to the imaged scenario geometry (flash distances and surface orientation) rather than the intrinsic optical properties of the lizard, the analysis was pursued with only the relative unit less quantities (S. Svanberg, personal communication). The intensity of the throat images was removed by a transformation of the colorspace from Cartesian to spherical which decreases dimensionality through removing the intensity dimension. Since the aim of the study was to quantify the red green blue (RGB) composition rather than the intensity of the throat colors the subsequent analysis was facilitated by the discarding of the intensity. To preserve the discrete patchy colors of the throat, the chromaticities of individual pixels were summarized in $2 \mathrm{D}$ histogram planes for each sample [56]. The histograms were decomposed using a principal component analysis [57], and the number of principal component planes included in the subsequent analysis was determined by the break point where the difference in the drop between successive eigenvalues is markedly smaller and evens out. Matlab $\left(\right.$ MathWorks ${ }^{\mathrm{TM}}$ ) was used for all image analyses.

We subsequently used a discriminant function analysis (DFA) to assess if the visually classified color morphs could be distinguished from each other using the principal component data that we extracted from the images. The software STATISTICA [58] was used for all analyses based on the principal component loadings for each lizard that were extracted from Matlab. We used Spearman rank order correlation to investigate if 

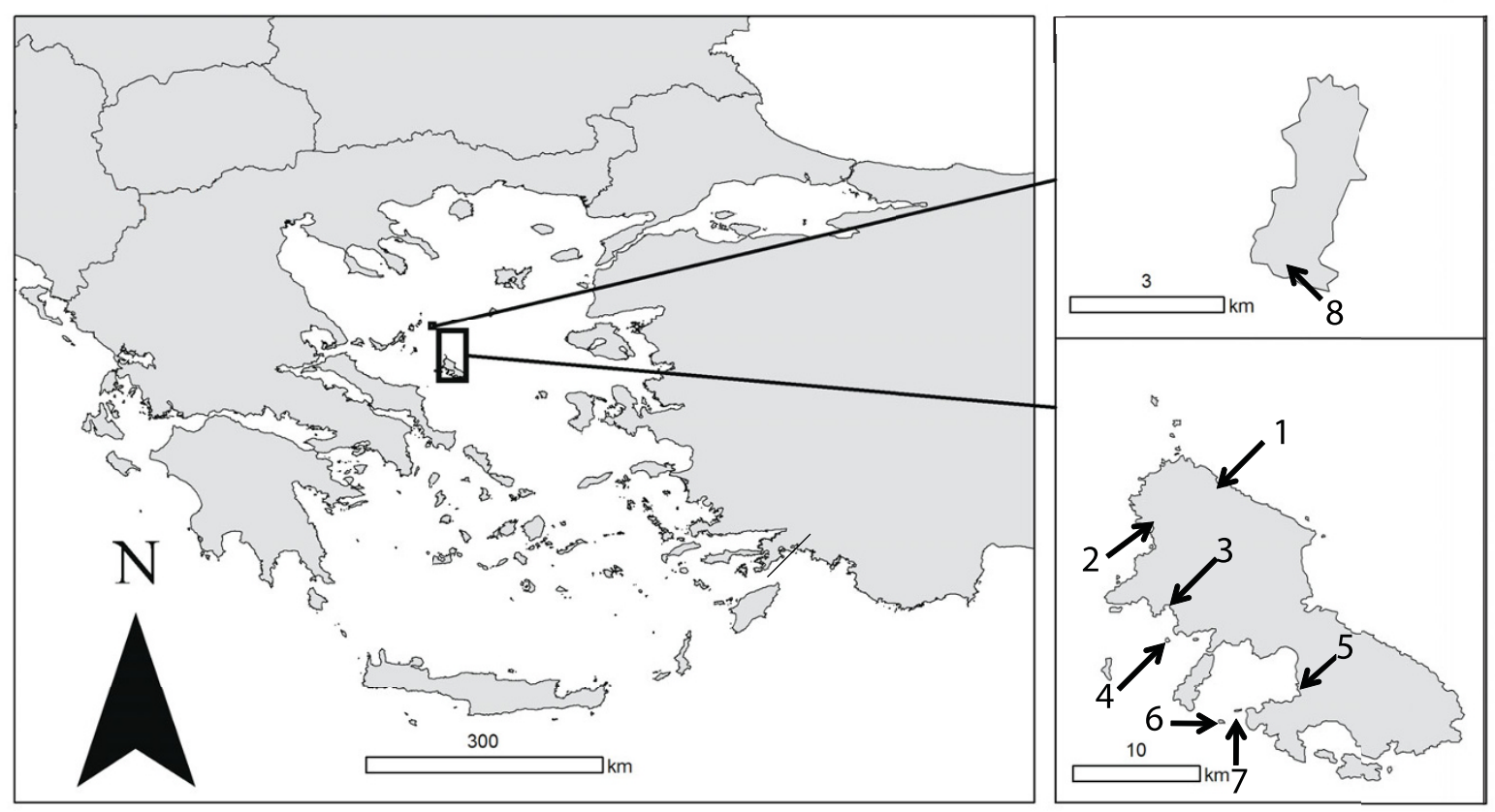
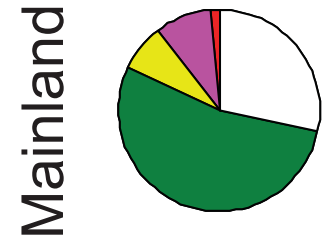

Agios Fokas 3

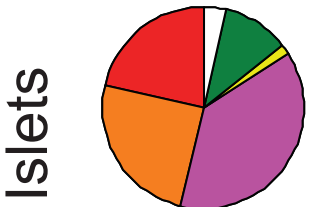

Lakonissi 4

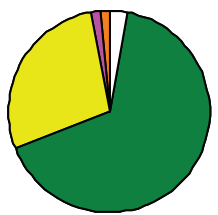

Nyfi 5

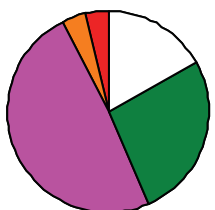

Mesa Diavates 6

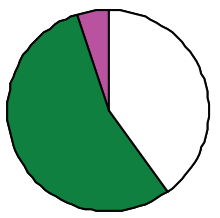

Atsitsa 3

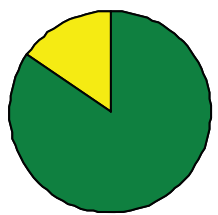

Exo Diavates 7

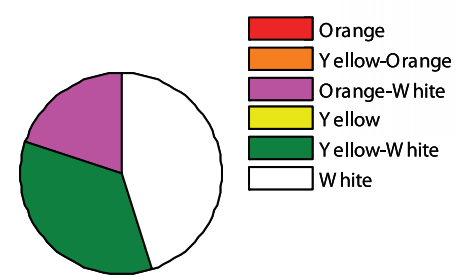

Palamari 1

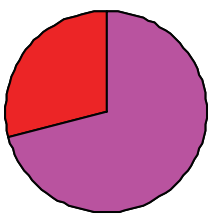

Piperi 8

Figure 2 Distribution of $P$. gaigeae and frequencies of the different throat color morphs in the populations. (A) Field sampling localities for P. gaigeae individuals. Map A shows Greece. The boxes, which are enlarged in map B and C, outline the island of Piperi and the island of Skyros, respectively. Field sampling sites are numbered from one to eight (1: Palamari, 2: Atsitsa, 3: Agios Fokas, 4: Lakonissi, 5: Nyfi, 6: Mesa Diavates, 7: Exo Diavates, 8: the island of Piperi). (B) Throat color morph frequencies among the seven populations of P. g. gaigeae and P. $g$. weigandi on Piperi. The upper row refers to populations from the main island of Skyros and the lower to islets close to Skyros and to the island of Piperi.

proportion of orange females was correlated to proportion orange males in each of the populations. We used $\chi^{2}$-tests to investigate if the frequencies of the throat color morphs differed among populations and between the habitat groups ("mainland" vs. "islets"). Our starting assumption was a simple (Mendelian) inheritance system: we thus assume that the throat color morph is governed by a single locus with three color alleles, codominant inheritance and hence six visible phenotypes. Based on this assumption, we also tested if the 
populations deviated from Hardy-Weinberg equilibrium with respect to the throat color morph frequencies, using $\chi^{2}$-tests.

Although we have no experimental data (e.g. breeding experiments) on the possible inheritance of throat color in this system, our assumption of a simple genetic basis of color is well-supported by several recent previous studies on color polymorphisms in both lizards and many other animal species (see references in Introduction). We do certainly not claim that there are no environmental effects on color and no role for phenotypic plasticity in these morphs. However, the discrete nature of these color morphs in combination with previous studies on animal coloration makes it highly likely that there is some genetic influence on coloration, perhaps through some major effect gene. Previous studies on color polymorphisms, including studies on birds, fish, lizards and many insect species indicate that variation in color is often heritable, and it is certainly not unusual that color polymorphisms are governed by simple systems of inheritance, e.g. single locus systems with several alternate alleles (see [22] for a recent review). In addition, our analyses do not rely on whether one- or two loci are involved in determining the throat color, but are based on the frequencies of the different alleles, and our results will thus not depend critically on the number of involved loci.

\section{DNA extraction and microsatellite typing}

DNA from all lizard samples was extracted with an ammonium acetate extraction protocol [59]. The DNA was quantified and diluted to $10 \mathrm{ng} / \mu \mathrm{l}$ and used as template in PCR reactions using 18 primers: Lv 319, Pb10, B4, C9, Lv 472, Pod 1B, B6, Pb73, Lv $4 \alpha$ Pod 2, Po47, Po56, Po55, Po22, Po11, Po43, Po51 and Po18 [60,61]. PCR reactions were carried out in a GeneAmp PCR system 9700 (Applied Biosystems Inc., Foster City, CA, USA) and the conditions used are specified in [61] and [60] respectively. The PCR products were separated and alleles were detected in an ABI PRISM 3730 capillary sequencer (Applied Biosystems). GeneMapper (Applied Biosystems) was used to determine the genotypes of the individuals.

\section{Molecular population genetic analyses}

We obtained genetic data from 289 individuals from the eight study populations (see Additional file 1 for breakdown of sample sizes for the different populations) and each of these individuals was scored at the 18 microsatellite loci. Departure from Hardy-Weinberg expectations and the genetic differentiation $\left(\mathrm{F}_{\mathrm{ST}}\right)$ between populations was estimated with FSTAT [62]. $\mathrm{F}_{\mathrm{ST}}$ for throat color morph was also calculated in FSTAT; the three colors were coded as alternative alleles at one locus. This analysis thus assumes that throat color is a heritable trait with Mendelian inheritance and codominant expression. We assumed that single color and combinations of two colors correspond to homo- and heterozygous stages, respectively. The program Structure version 2.2 [63] was run on individual multilocus genotypes for a number of clusters $K$ ranging from 1 to 12 using a burn-in length of 50,000 and a run length of 100,000 iterations. The likelihood for the data given each of $K$ clusters was recorded, but since the main aim of the analysis was to illustrate the degree of genetic differentiation between populations rather than to find the number of genetic clusters for which the likelihood is highest, the additional method [64] for determining $K$ was not applied. Effective population size $\mathrm{N}_{\mathrm{e}}$ was estimated with LDNE [65]. AMOVAs were performed in Arlequin version 3.3 [66] to evaluate the within- and among group genetic variance. Isolation-by-distance was tested using Mantel's test implemented in the ISOLDE application in the program GENEPOP [67]. We used a general linear model (GLM) with color morph $\mathrm{F}_{\mathrm{ST}}$ as dependent variable and neutral $\mathrm{F}_{\mathrm{ST}}$ and category (mainland-mainland, mainland-island and island-island) as main effects and used a design including all the two-way combinations as well as the three-way combination, to test both for dependence on the two main effects and interactions between them. Since each population is involved in more than one comparison the data points are not independent, so we used a resampling approach [68] to confirm these results. We also used regressions to test for a correlation within the individual categories mentioned above, and used resampling statistics [68] to confirm our results since the data points are interdependent. The resampling procedure confirmed the results from the GLM, and hence we only present the results from the latter in this study. We thus compared the $\mathrm{F}_{\mathrm{ST}}$-values calculated from the color morphs ("morph divergence") and the $\mathrm{F}_{\mathrm{ST}}$-values based on the 18 microsatellite loci ("neutral divergence").

Selection can be inferred from the genetic signature of different molecular markers; markers that have been under directional selection are expected to be more diverged than neutral markers and markers that have been subjected to stabilizing selection should be less diverged $[44,45]$. Recently, it has been argued that comparisons of population divergence between putatively adaptive traits (often referred to as "Q $\mathrm{QST}_{\mathrm{ST}}$ ) and neutral population divergence $\left(\mathrm{F}_{\mathrm{ST}}\right)$, should utilize the whole neutral $\mathrm{F}_{\mathrm{ST}}$-distribution to see if the adaptive traits fall within this distribution, before the null hypothesis of genetic drift can be safely rejected $[16,44]$. We follow these recommendations and visualized the entire neutral $\mathrm{F}_{\mathrm{ST}}$-distribution and its relationship to our adaptive trait (color morph divergence). We used a paired t-test to 
investigate if $\mathrm{F}_{\mathrm{ST}}$ for throat color morph differed from the $\mathrm{F}_{\mathrm{ST}}$ for the microsatellite loci. This procedure assumes that the pair-wise population comparisons are statistically independent, which is questionable, since each population is involved in several different comparisons. We therefore confirmed the results from the paired $t$-test using the re-sampling procedure described above [68], but our conclusions remained the same (see Results). To investigate if the morph frequencies on the islets have evolved in parallel, we performed a logistic regression with a binomial distribution and a logit link, where orange allele or not orange allele is the dependent variable and habitat (islet or mainland) the main effect. The subspecies $P$. g. weigandi was not included in this analysis since the habitat of Piperi is expected to differ from that of Skyros and its' surrounding islets and thus not reflect an islet- or mainland habitat effect.

\section{Results}

Color morphs: visual classification and spectral analysis

A discriminant function analysis based on the seven first principle components extracted from the throat images revealed that the six visually classified throat color morph groups were highly statistically different from each other $(F=31.81$, df $=7,318, P<0.001)$ (Fig. 3). 14 out of 15 post-hoc tests between the different groups were highly significant $(P<0.001)$, with the only exception for the yellow-orange morph that did not differ from the orange $(P=0.11)$. The results from these analyses, showing variation from the first two canonical roots is depicted in Fig. 3. Of the six phenotypes that were clearly separated from each other, the confidence ellipses of the three "pure" morphs (putative homozygotes) are also shown (Fig. 3).

\section{Geographic variation in color morph frequencies}

Color morph frequencies differed significantly between all eight populations $\left(\chi^{2}=1168, \mathrm{df}=35, P<0.001\right)$. The frequencies also differed significantly between the mainland group and islet group within the subspecies $P$. g. gaigeae $\left(\chi^{2}=336, \mathrm{df}=5, P<0.001\right)$ (Fig. $\left.2 \mathrm{~B}\right)$. All main colors $(\mathrm{O}, \mathrm{Y}, \mathrm{W})$ - although not all six throat color morphs - were found in all mainland populations and in two of the three islet populations of P. g. gaigeae (Fig. $2 \mathrm{~B})$. On the third islet, only 16 individuals were sampled, and we only found $\mathrm{Y}$ and $\mathrm{W}$. In the other subspecies $(P . g$. weigandi), only $\mathrm{O}$ and $\mathrm{W}$ were found $(\mathrm{N}=$ 31 ). We found a significant positive relationship ( $\beta=$ 0.88; $P<0.05$ ) between the proportion of females in the populations with partly or fully orange throats (e. g. O, YO, OW individuals) and the proportion of males with partly or fully orange throats (Fig. 4). This suggests that the color polymorphism in this species is present in both males and females and that it is not sex-limited in its expression. None of the eight populations differed significantly from Hardy-Weinberg expectations with respect to local throat color morph frequencies (Additional file 2).

\section{Genetic population differentiation}

Pair-wise population comparisons of neutral genetic variation ( $\mathrm{F}_{\mathrm{ST}}$-values between populations) ranged from 0.0057 to 0.52 when $P$. g. weigandi was included and between 0.0057 and 0.36 within P. g. gaigeae only (Table 1). All between-population comparisons of neutral divergence were highly significant $(P<0.001) . \mathrm{F}_{\mathrm{ST}^{-}}$ values estimated from the color morph frequency data ranged from 0.0025 to 0.45 when all populations and $P$. g. weigandi were included, and between 0.0025 and 0.24 within P. g. gaigeae only (Table 1 ).

We used the microsatellite data and STRUCTURE [63] to illustrate the degree of genetic population structure and to infer the number of genetically independent populations (or "clusters"; $K$ ) that we could find support for in our data set (Fig. 5). The likelihood of data LnP (D) stabilized within 20,000 iterations for all tested values of $K$, and thus a run length of 100,000 was deemed as sufficient. The clusters defined by STRUCTURE correspond to a sampling locality or a group of sampling localities up to $K=6$ (Fig. 5A) and the loglikelihood-values reached a plateau at $K=6$ (Fig. 5B). At $K=7$ all sampling localities were well defined, with the exception of the two most northern mainland populations that included a majority of individuals assigned to two different genetic clusters (populations 1 and 2 on the map). At $K=2$, two of the island populations form a separate cluster and at $K=3$ the $P$. $g$ weigandi population form a third cluster. The next two clusters to form are the remaining island populations, and at $K=6$ the southern mainland population separates from the three northern mainland populations (Fig. $5 \mathrm{~A}$ ).

Estimates of effective population sizes $\left(\mathrm{N}_{\mathrm{e}}\right)$ based on all allele frequencies $>0.01$ varied between 39.4 and 97.7 for the islet populations of P. g. gaigeae and between 315.3 and 375.0 for the mainland (Skyros) populations (Table 2). The $\mathrm{N}_{\mathrm{e}}$ of $P$. g. weigandi and two of the northern mainland populations of $P$. g. gaigeae could not be accurately estimated due to either a too high noise-to-signal ratio or a very large population size. Using 0.02 or 0.05 as lowest frequency of alleles included in the analysis yielded similar results (data not shown).

Most of the genetic variance was found within populations (more than 75\%; Table 3). The variance was low among groups $(2.6 \%)$ but higher among populations $(14.9 \%)$ when the populations were divided into an island and a mainland group (Table 3). When the mainland populations were grouped in two populations 


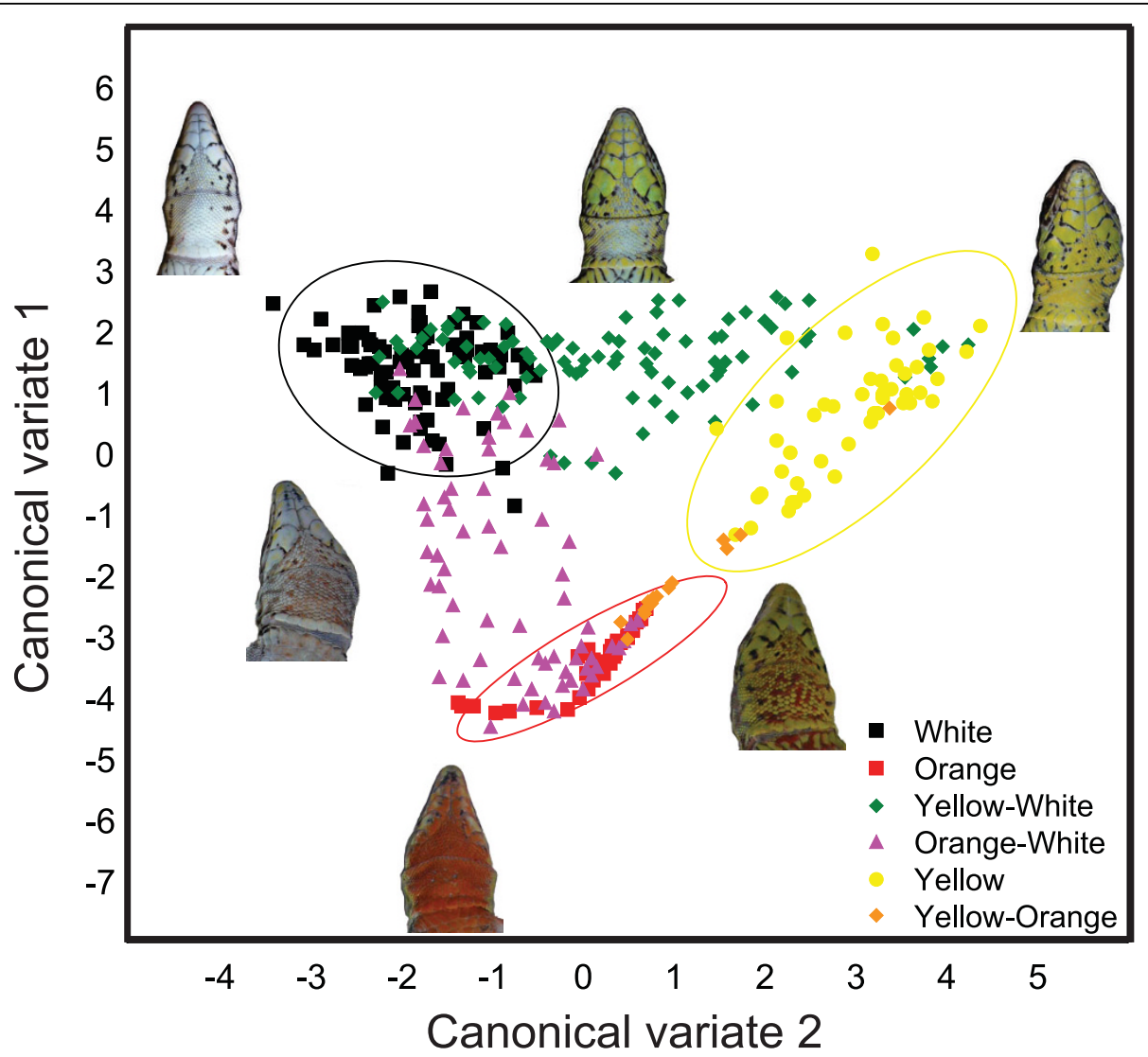

Figure 3 Discreteness of throat color morphs. Canonical roots (CV) of throat color morphs. Lizards were classified to one out of six possible morphs visually (symbols) and the canonical roots (CV1 and CV2) were calculated from the spectral information that we obtained from RGB photographs. Shown are $95 \%$ confidence ellipses for the three "pure" or putatively 'homozygous' throat color morphs $(\mathrm{O}, \mathrm{W}$ and $\mathrm{Y})$.

(north and south), both the between-group (1.6\%) and the among-population variance $(2.3 \%)$ were low (Table 3 ). When the islets were divided into two groups (northern and southern), the between-group variance was still rather low (6.8\%), but among-population variance (23.3\%) was nevertheless an order of magnitude higher than the among-population variance when only the mainland populations were included in the analysis (Table 3). This pattern of within- and among-population variation is consistent with a scenario where the islet populations have lost different components of the genetic variance, presumably a result of their lower effective population sizes (Table 2). The mainland populations of P. g. gaigeae showed a pattern of differentiation consistent with isolation-by-distance (Mantel's test; $y=-0.27+0.033 \times \ln ($ distance $), P=0.04)$. There was no such trend when the islet populations of $P$. g. gaigeae, or when $P$. g. weigandi and the islet populations, were included in the analysis, however (Table 4).

Color morph divergence was significantly correlated with neutral genetic divergence across all populations
$(F=6.37 ; \mathrm{df}=1,26 ; P=0.02)$. When we separated these comparisons into three different geographic categories (mainland-mainland, mainland-island and islandisland), we found a significant positive relationship within two of these categories (Fig. 6A). The mainlandmainland and mainland-island comparisons were both positive and significant, whereas the island-island comparison was non-significant (Fig. 6A). The interaction term between geographic category and neutral divergence was significant $(F=7.5 ; \mathrm{df}=4,48 ; P=0.003)$, indicating that the correlation between color morph divergence and neutral divergence differed between the geographic settings (Fig. 6A).

Mean $\mathrm{F}_{\mathrm{ST}^{-}}$-values of color morph frequencies clearly fell within the range of the mean $\mathrm{F}_{\mathrm{ST}}$-values based on each one of the 18 microsatellite loci (Fig. 6B). No difference was found between $\mathrm{F}_{\mathrm{ST}}$ based on color morph frequencies and $\mathrm{F}_{\mathrm{ST}}$ based on neutral genetic divergence (Paired t-test: $t=0.91 ; \mathrm{df}=27 ; P=0.37$; results remained the same after resampling). Hence these data do not allow us to firmly exclude that population 


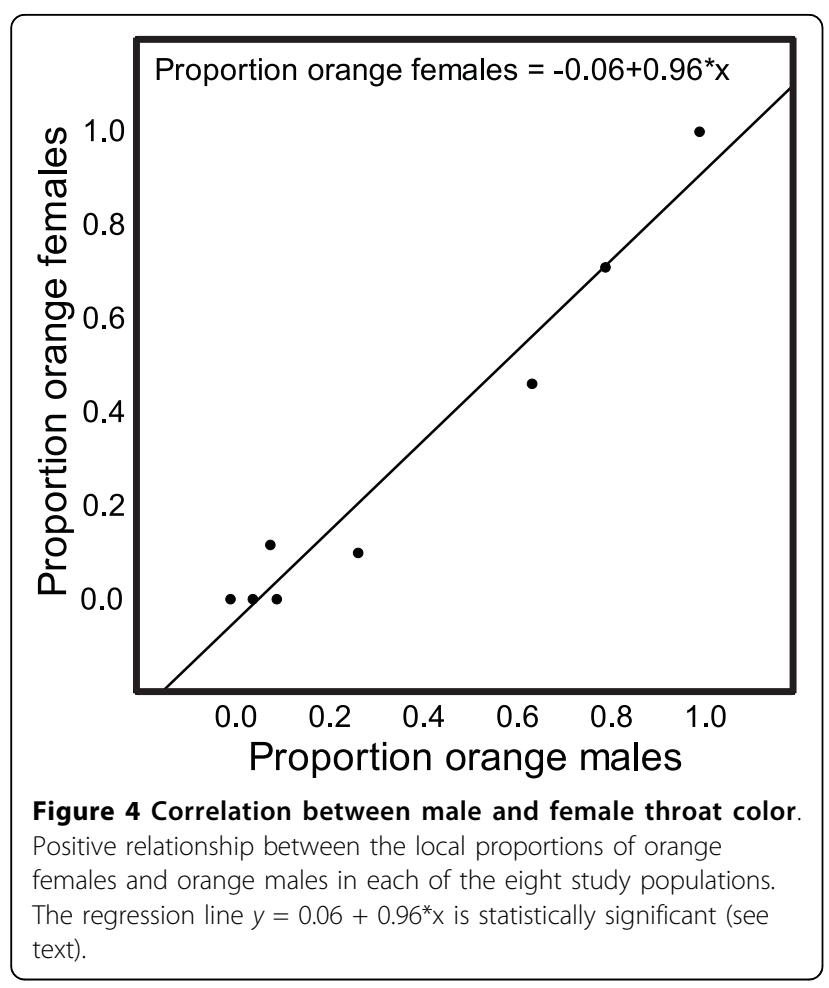

divergence in color morph frequencies have been affected solely by genetic drift. This conclusion remains the same if the categories are analyzed separately (all $P$ values $>0.05$ ). Islet populations had a significantly higher proportion of orange throat color alleles than mainland populations (logistic regression: $\chi^{2}=112.91$; $\mathrm{df}=1 ; P<0.001)$, although no orange throat color alleles were found on one of the three islets.

\section{Discussion}

What is the role of genetic drift in phenotypic evolution, if any? Even if most evolutionary biologists have strong reasons to believe that genetic drift is a weak force in phenotypic evolution, in comparison to selection $[69,70]$, genetic drift can still influence trait variation that later becomes visible to selection [23]. For example,

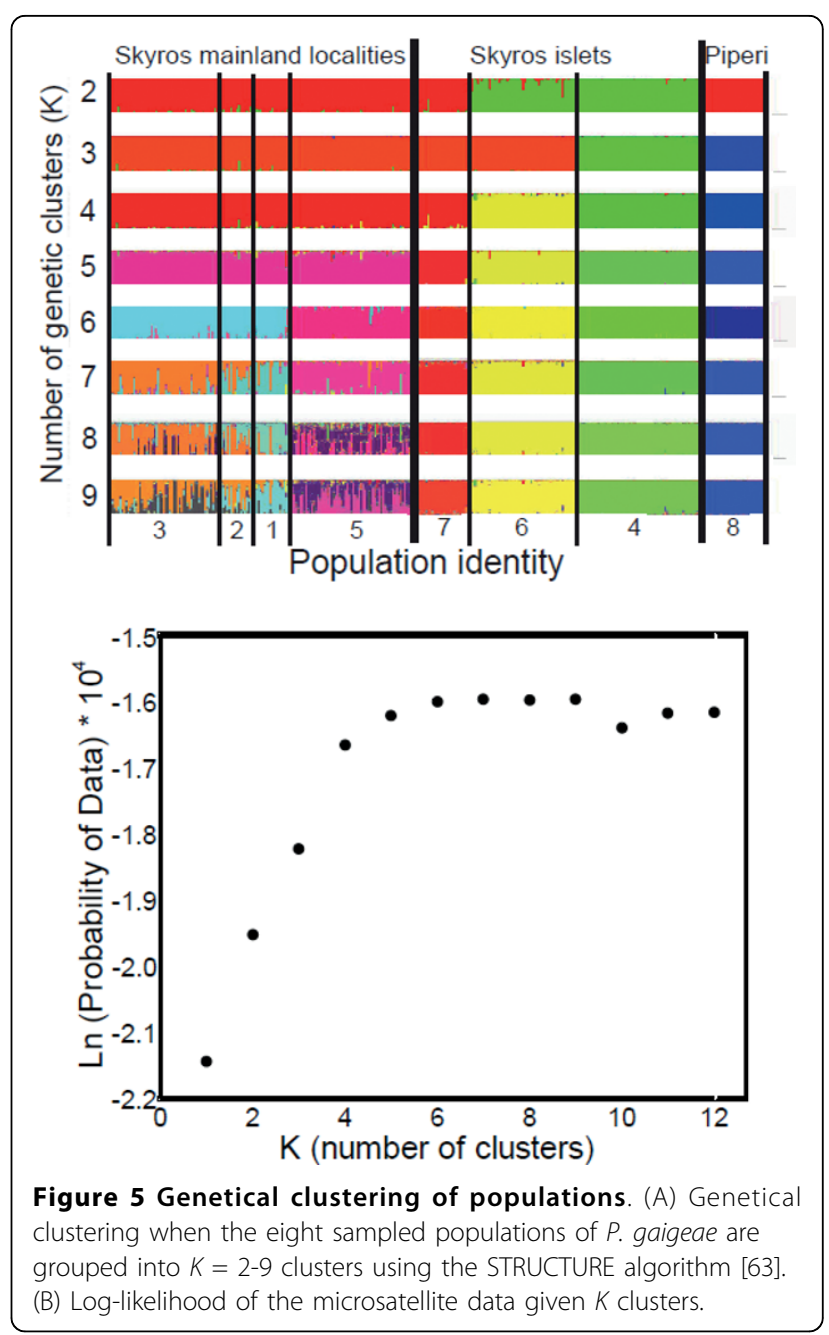

the loss of a particular color morph might change the social selective environment, particularly when color is used in intra- or intersexual signaling [46,71]. Genetic drift in sexually selected traits in isolated populations might lead to profound consequences upon secondary contact. Since sexually selected characters can diverge along a neutral line of equilibrium [72], genetic drift in

Table $1 \mathrm{~F}_{\mathrm{ST}}$ for neutral genetic variation and throat color morph

\begin{tabular}{|c|c|c|c|c|c|c|c|c|}
\hline Population & Agios Fokas & Atsitsa & Mesa Diavates & Exo Diavates & Lakonissi & Nyfi & Palomares & Piperi \\
\hline Agios Fokas (M) & & 0.0165 & 0.1530 & 0.1002 & 0.2249 & 0.0261 & 0.0286 & 0.2941 \\
\hline Atsitsa (M) & 0.0025 & & 0.1908 & 0.1096 & 0.2587 & 0.0486 & 0.0057 & 0.3399 \\
\hline Mesa Diavates (I) & 0.0727 & 0.0821 & & 0.2196 & 0.3641 & 0.1486 & 0.1970 & 0.4206 \\
\hline Exo Diavates (I) & 0.0850 & 0.1655 & 0.2030 & & 0.3300 & 0.0726 & 0.1287 & 0.3632 \\
\hline Lakonissi (I) & 0.1990 & 0.2404 & 0.0830 & 0.2205 & & 0.2515 & 0.2561 & 0.5200 \\
\hline Nyfi (M) & 0.1178 & 0.1930 & 0.2353 & 0.0088 & 0.2417 & & 0.0488 & 0.2729 \\
\hline Palomares (M) & 0.0234 & 0.0031 & 0.0493 & 0.2181 & 0.2191 & 0.2452 & & 0.3365 \\
\hline Piperi (I) & 0.3376 & 0.3859 & 0.1383 & 0.4501 & 0.0711 & 0.4510 & 0.3333 & \\
\hline
\end{tabular}

$\mathrm{F}_{\mathrm{ST}}$-values based on 18 microsatellite loci (upper right half) and $\mathrm{F}_{\mathrm{ST}}$-values based on throat color phenotype frequency in the population (lower left half). Mainland localities are abbreviated with a $\mathrm{M}$ and island locals with an I. 
Table 2 Effective population sizes

\begin{tabular}{lccc}
\hline Population & $\mathbf{N}_{\mathbf{e}}$ & Lower 95\%Cl & Upper 95\%Cl \\
\hline Mainland 1 (AF) & 315.3 & 202.7 & 669.9 \\
Mainland 3 (AT) & - & - & $\infty$ \\
Island 2 (D) & 97.7 & 66.3 & 170.0 \\
Island 3 (DII) & 39.6 & 27.1 & 66.7 \\
Island 1 (L) & 39.4 & 29.7 & 54.6 \\
Mainland 2 (N) & 375.0 & 240.8 & 802.9 \\
Mainland 4 (P) & - & 177.0 & $\infty$ \\
P. g. weigandi & - & 288.2 & $\infty$ \\
\hline
\end{tabular}

Estimated effective population size $\left(\mathrm{N}_{\mathrm{e}}\right)$ for the studied populations. Alleles with frequencies above 0.01 were included in the analysis.

sexually selected characters can result in sexual isolation between populations as a by-product of sexual selection within populations [11]. An interaction between sexual selection and genetic drift is of particular interest in the present study as well as in other lizard species, since throat color in lizards has been found to be correlated with immunological condition and color could thus function as a sexually selected honest signal both within and between the sexes [73].

Comparisons of phenotypes from island and mainland populations played a central role in Ernst Mayr's theory of founder effect speciation $[1,74]$ and continues to inspire contemporary evolutionary biologists today [75]. For instance, island biology studies of enigmatic color morphs in Dendrobates frogs have shown an impressive color morph diversity in the archipelago of Bocas del Toro, outside Panama, compared to mainland Central America [76]. The discrete throat color phenotypes in $P$. gaigeae and the natural geographical replicates (i.e., different islet populations), as well as the variation in throat color throughout the Balkan clade of Podarcis where the sister species $P$. milensis does not exhibit throat color morphs whereas for example $P$. melisellensis has retained it, make this an excellent study system to address how selective processes operate in subdivided islet populations.

A role for phenotypic plasticity in determining the throat color morphs in P. gaigeae can not be excluded. If throat color morph would be entirely plastic with no heritable basis, the significant correlations between neutral genetic variation and the throat color morph
Table 4 Isolation by distance

\begin{tabular}{lccc}
\hline Group & a & b & $\boldsymbol{P}$ \\
\hline P. g. gaigeae and P. g. weigandi & -0.98 & 0.13 & 0.11 \\
P. g. gaigeae & 0.53 & -0.04 & 0.65 \\
P. g. gaigeae mainland & -0.27 & 0.03 & 0.04 \\
\hline
\end{tabular}

Isolation by distance, where population differentiation $\left(F_{S T}\right)=a+b^{*} \mid n$ (geographical distance $(\mathrm{km})$ ). $P$-values are from Mantel's tests.

frequencies for mainland-mainland and islet-mainland population pairs (Fig. 6A) would still need an explanation. One possibility might be that these correlations could reflect habitat differences between populations that have diverged to different degrees and at a rate that is proportional to molecular divergence. One could possibly argue for this possibility on the main island if there would be a clinal change in habitat. However, such a correlation would not necessarily be expected between the islet-mainland population pairs since the similarity in habitat between the islets and mainland locals is unlikely to be proportional to the time since the islets were isolated from the mainland. Rather, the environments on the islets depend more on local factors such as soil type and anthropogenic impact such as grazing pressure from goats (A. Runemark and E. Svensson, unpublished observations). Although we do not exclude the existence of genotype-by-environment interactions, a scenario with no heritable basis at all for the throat color polymorphism seems quite unlikely. With the caveat that we have no data from breeding experiments on the genetic basis of this throat color polymorphism, the discrete nature of these color morphs (Fig. 3), the strong correlation in throat color between the sexes (Fig. 4), our findings that none of the populations deviate from Hardy-Weinberg proportions with respect to the throat color morphs (Additional file 2), and the significant relationship between population divergence of the throat color morphs and neutral genetic divergence (Fig. 6A), is consistent with a heritable basis of throat color. Previous studies on several other lizard species have often found indications of a relatively simple genetic architecture of color morphs [30-34]. Although we do not know the exact number of loci involved in determining the throat color, the results are based on allele frequencies, and even if more than

Table 3 Partitioning of genetic variance

\begin{tabular}{lccc}
\hline Grouping & Among groups & Among populations & Within populations \\
\hline Mainland $(1,2,3,5)$, Islets $(4,6,7)$, P. g. W (8) & 10.31 & 13.91 & 75.78 \\
Mainland $(1,2,3,5)$, Islets $(4,6,7)$ & 2.61 & 14.89 & 82.50 \\
North mainland $(1,2,3)$, South mainland (5) & 1.63 & 2.37 & 96.0 \\
North islet (4), South islets $(6,7)$ & 6.82 & 23.32 & 69.86 \\
\hline
\end{tabular}

AMOVA for genetic variance for different groupings of the studied populations. Variance is partitioned into among group variation, among population variation and within population variation. 

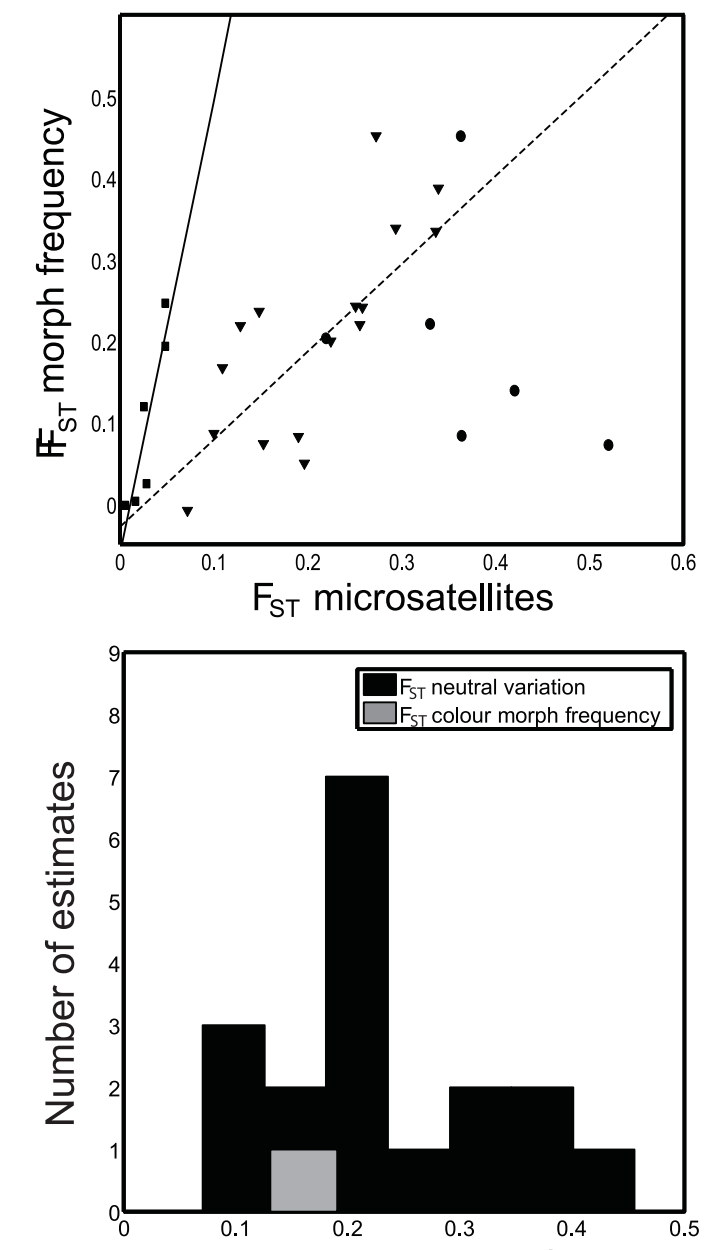

$\mathrm{F}_{\mathrm{ST}}$ distribution and $\mathrm{F}_{\mathrm{ST}}$ colour morph

Figure 6 Relationship between neutral divergence and morph divergence. (A) Relationship between the pair wise population comparisons $\left(F_{S T}\right)$ calculated from color morph frequencies (assuming a single locus character) and neutral genetic divergence ( $F_{\text {ST }}$ obtained from 18 microsatellite loci). The relationship is positive and statistically significant when data from all categories are included: $y=0.09+0.44^{*} x ; r^{2}=0.20 ; F=6.37 ; \mathrm{df}=1,26 ; P=0.02$. There is also a significant relationship when only the mainland populations are included (squares; full line; $y=-0.07+5.59^{*} x ; r^{2}=$ $0.83 ; F=19.41 ; \mathrm{df}=1,4 ; P=0.01)$ and when only mainland-island comparisons are included (triangles; dashed line; $y=-0.04+1.19^{*} x$; $\left.r^{2}=0.60 ; F=21.01 ; \mathrm{df}=1,14 ; P=0.0004\right)$. There is no significant relationship between color morph divergence and neutral divergence when only island populations are compared (dots). (B) Distribution of mean pair wise $\mathrm{F}_{\mathrm{ST}}$-values for the 18 microsatellite loci (black) and the mean pair wise $\mathrm{F}_{\mathrm{ST}}$-values that were calculated from the throat color morph frequencies (assuming a single locus character; (in white)).

one locus would determine the throat color, it would not qualitatively change our conclusions, as long as there is some genetic basis to the polymorphism (e. g. a major-effect-gene). Based on the evidence above we tentatively assumed a simple genetic basis, and investigated if the data on the spatial distribution of these color morphs is consistent with the neutral expectation, and that stochastic factors alone might responsible for the population differentiation.

In the genus Podarcis several, if not most, species exhibit throat color polymorphism which indicates that these polymorphisms might have survived several lineage splitting and speciation events [48], (Fig. 1). When a polymorphism has been retained from a common ancestor it is highly unlikely to be entirely selectively neutral because strong overdominance or negative frequencydependent selection is required to maintain all morphs in such systems [77-79], and selection on traits, including color polymorphisms, is usually a strong force [14]. Thus, it is probable that there is long-term balancing selection that maintains the throat color morphs in $P$. gaigeae and other Podarcis-species. In addition, if throat color morph was selectively neutral it would be highly unlikely that all three alleles would be present on all mainland locations and two out of three islets. Consistent with such a scenario where selection acts in a stabilizing fashion, the frequencies of the throat color morphs were quite similar across all the mainland populations on Skyros (Fig. 2B). Interestingly, the orange throat color morphs were overrepresented on the islets compared to the mainland populations (Fig. 2B). These differences between mainland and islet populations could potentially be a result of different local selective environments on the islets or islet specific genotype by environment interactions if such exist, although we have no direct ecological data in support of this. Subdivided populations with limited effective population size are, however, also affected by genetic drift [80]. Thus, the differences in throat color morph frequencies between the geographically close islet populations with similar habitats (Figs. 2A-B) could potentially partly be a result of stochastic processes.

Random fluctuations due to genetic drift can result in a form of environmental noise that can in turn fuel selection. For instance, when negative frequency-dependent selection operates in a system with environmental noise, perturbations in one direction can generate strong backlashes, which in turn can fuel selection and cause rapid evolutionary dynamics [25]. When the selective signal is weak and environmental noise is high, stochastic factors might partly and temporarily overcome the selective signal (see for example [80]). Stochastic effects such as genetic drift have a larger impact when population size is small [17], as each stochastic death implies a larger change in the allele frequency distribution. Moreover, when one of the alleles is maintained at a low frequency at stable evolutionary equilibrium, selection may accelerate the loss of the rarest allele by random genetic drift [17]. In several other color polymorphic systems, 
including species with continuous distributions and large population sizes, the frequency of the different color morphs sometimes shows patterns which are not distinguishable from the expectations under a scenario of genetic drift $[7,9,23]$. In addition to genetic drift, other forms of stochasticity can also operate and affect allele frequencies, even in large populations [12]. These forms of stochasticity include demographic stochasticity and stochasticity generated by life-history variation among genotypes [12].

Three different lines of evidence suggest that genetic drift might partly be responsible for the divergence in throat color morph frequencies between the islets given that the throat color polymorphism is heritable (Fig. 2B). First, the effective population sizes on the islets are very low (Table 2 ; All $\mathrm{N}_{\mathrm{e}}: \mathrm{s}<100$ ). In such small populations, stochastic frequency fluctuations in selected alleles might under some periods temporarily override the effects of selection [80]. With an effective population size of approximately 40 individuals, as is the case for one of the islets, there are only 80 throat color alleles present and random loss of only a few individuals could potentially have large effects on the overall population allele frequency. Second, the $\mathrm{F}_{\mathrm{ST}}$-values of traits subjected to directional selection are expected to differ sig-

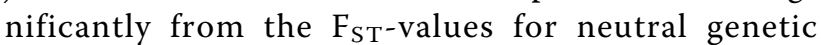
variation $[44,45]$. The $\mathrm{F}_{\mathrm{ST}}$ for throat color morph frequency fell in the lower range of the distribution of the $\mathrm{F}_{\mathrm{ST}}$-values for neutral genetic variation (Fig. 6B). Comparisons of population divergence for different sets of loci are useful for identifying loci under directional selection [44], although the large confidence intervals which sometimes overlap zero can make it difficult to infer stabilizing selection with this approach [81]. The overall high neutral $\mathrm{F}_{\mathrm{ST}}$-value for this lizard species (0.208) should, however, increase our statistical power to detect stabilizing selection in this system that might have favored a certain stable morph frequency equilibrium in all populations. Third, we found a significant positive correlation between the population differentiation in throat color and neutral genetic divergence (Fig. $6 \mathrm{~A}$ ). If selection would mainly explain the population morph frequency differences, we would not necessarily expect a change in genome-wide neutral genetic variation. Selection pressures to maintain a stable morph frequency across all populations might be the appropriate null expectation of population divergence for polymorphisms that transcend species boundaries, and when alleles are maintained by negative frequency-dependent selection [77-79]. If this is the case also for a trait like this color polymorphism, we would expect a pattern of population divergence for color morphs that would be significantly less than the neutral expectation at evolutionary equilibrium [15].
We do certainly not claim, based on these results, that genetic drift is the only evolutionary force operating on this color polymorphism. An additional role for selection and possibly for phenotypic plasticity can certainly not be excluded. Although indirect inferences about the action of selection are useful and have been used successfully by many workers in the past [15,82-84], such indirect approaches suffer from several limitations, among them low statistical power $[45,81]$. Failure to reject the drift-expectation for color morph divergence in this study (Fig. 6B) does thus not justify any strong claim that selection does not operate at all on these color morphs. Rather, we suggest that selection on these morphs, at least on the small islets, is not strong enough to result in a significant adaptive signal when we compared adaptive divergence and neutral divergence. Although genetic drift is usually considered by many population geneticists to be a weak force compared to selection $[69,70]$, we tentatively suggest that an interaction between genetic drift and local natural or sexual selection is most likely explanation for the spatial patterns in our data. Genetic drift could change trait frequencies when selection is temporally relaxed, an ecological scenario that is likely to be quite common and which might exist in this system, for instance, when lizard populations invade novel island environments with fewer predators. We can not disentangle the relative contributions of genetic drift and founder effects based on our findings in this study. Since the sea level in the Aegean Sea has been rising and sinking [52,53] a scenario where lizards populations were isolated when land bridges were submerged and subsequently lost genetic variation due to low effective population sizes is probably more plausible than a pure founder event scenario, though.

The physical and biotic environments differ substantially among these small islets, which could generate novel selection pressures compared to the mainland. For instance, the predator faunas (birds and snakes) are more depauperate on the islets, and the seabird colonies on the islets might alter the nutrient cycles considerably, which in turn might affect the quantity and quality of the food sources of the lizards [50]. It is possible that the islet populations have adapted locally to meet the requirements of these island specific environments, or that genotype-by-environment-interactions result in certain colour morphs becoming expressed more often in certain environments. The vegetation on the islands in the Skyros archipelago differs substantially even among nearby islets, which might partly reflect stochastic factors and reveal some degree of community drift [75]. For instance, some common plant taxa are lacking entirely on some of the islets, whereas the abundance of other plant taxa is much higher on some of the islets 
than on the mainland [55]. Although these different habitat features might potentially favor different throat color morphs on different islets, the mainland populations also differ in many environmental variables, such as type of substrate, grazing pressure, vegetation cover and predator faunas (A. Runemark \& E. I. Svensson, unpublished observations).

After the geographic isolation of $P$. g. weigandi from $P$. g. gaigeae, the orange morph increased in frequency on Piperi (Figs. 2A-B), perhaps as a result of founder events, genetic drift, or because of local selection favoring that morph in this novel island environment. If the different throat color phenotypes are genetically correlated to other physiological, morphological or behavioral traits, which is the case in $U$. stansburiana $[26,28,32,85]$ or in immune response as is the case for $P$. muralis [27], one or several of the throat color morphs in the ancestral population could initially and due to chance alone, have been better adapted to the novel environments. Such "pre-adapted" morphs might then subsequently rise in frequency through phenotype sorting $[86,87]$, either by selection alone or due to an interaction between selection and genetic drift. The loss of one or more color morphs has occurred several times in different populations of $U$. stansburiana [46,71], and it might also operate in the Balkan clade of Podarcis (see e. g. P. milensis in Fig. 1; [48]).

If genetic drift can affect phenotypic divergence in characters such as throat color which are often genetically correlated with other traits (see discussion above), genetic drift could potentially indirectly also change the optimal strategies for the remaining morphs since the selective environment will change if one morph and its strategy is removed. For instance, populations of $U$. stansburiana, which have lost morphs and become monomorphic, differ from the polymorphic populations with respect to sexual size dimorphism and potentially sexual selection [70]. Thus, the loss of one or several morphs might cause rapid divergence following a change in social selective environment in lizards. Polymorphic types within a population can thus potentially serve as starting material for new species $[47,88,89]$ and the potential loss of the yellow throat color morph in the subspecies P. g. weigandi is interesting from this point of view.

\section{Conclusions}

The color morph frequency in P. gaigeae differs among populations, with more pronounced frequency differences among islet populations. This might indicate a role for local genetic drift on color morph frequency divergence, although it is likely that these color morphs are maintained by long-term balancing selection, given the trans-species nature of these polymorphisms.
Comparisons of neutral and morph frequency divergence did not reveal any evidence for either directional or stabilizing selection, which might partly be explained by the low statistical power and weak selection, rather than color morphs being entirely neutral. We therefore suggest that an interaction between selection and genetic drift explains the patterns of divergence in throat color morphs. In isolated populations with small effective population size, genetic drift is particularly likely to operate and to interact with selection which might cause divergence even in phenotypic characters.

\section{Additional material}

Additional file 1: Number of photographed males and females per population. Contains breakdown sample sizes for number of individuals per population and sex for which throat color morph was determined.

Additional file 2: Tests for deviation from Hardy-Weinberg equilibrium per population. Contains tests for deviations from HardyWeinberg equilibrium for all populations and the breakdown sample sizes for number of genotyped individuals per population.

\section{Acknowledgements}

We thank Kostas Sagonas and Steffi Weinhold for assistance in the field, Mikkel Brydegaard for assistance with optical measurement techniques, and Tobias Uller and the Svensson Lab for constructive comments on the manuscript. We are also very grateful to our helpful captains on Skyros for transportation to islands in the Skyros archipelago, and to the National Sea Park of Alonissos North Sporades for the permission to work in the national park and for the transportation to the island of Piperi.

Funding was provided from Kungliga Fysiografiska Sällskapet (AR), Helge Ax: son Johnsons Stiftelse (AR), Stiftelsen Lars Hiertas Minne (AR),

Naturvetenskapliga Fakultetens Rese- och Forskningsstipendier (AR) and the Swedish Research Council (EIS).

\section{Author details}

${ }^{1}$ Section for Animal Ecology, Ecology Building, Lund University, SE-223 62 Lund, Sweden. ${ }^{2}$ School of Natural Resources and Environment, University of Michigan, Dana Building, 430 East University, Ann Arbor, Ml 48109-1115, USA. ${ }^{3}$ Modern Greek Program, Department of Classical Studies, 2160 Angell Hall, University of Michigan, 435 S. State, Ann Arbor, MI 48109-1115, USA. ${ }^{4}$ Section of Animal and Human Physiology, Department of Biology, University of Athens, Panepistimiopolis, 15784 Athens, Greece.

\section{Authors' contributions}

AR participated in the design of the study, carried out the field work, the color measurements and spectral analysis, the genetic analysis and drafted the manuscript. BH planned the genetic labwork and helped out with the design and conduction of the genetic analysis. PP and EDV helped out with the field work. EIS conceived of the study, and participated in its design and and helped to draft the manuscript. All authors read and approved the final manuscript.

Received: 10 December 2009 Accepted: 2 September 2010 Published: 2 September 2010

\section{References}

1. Barton NH, Charlesworth B: Genetic Revolutions, Founder Effects, and Speciation. Annual Review of Ecology and Systematics 1984, 15:133-164.

2. Barton N: Natural selection and random genetic drift as causes of evolution on islands. Philosophical Transactions of the Royal Society of London B Biological Sciences 1996, 351:785-795. 
3. Gavrilets S: Fitness landscapes and the origin of species Princeton, NJ. Princeton University Press 2004

4. Nei M, Maruyama T, Wu C-I: Models of Evolution of Reproductive Isolation. Genetics 1983, 103:557-579.

5. Templeton AR: Mechanisms of Speciation A Population Genetic Approach 1981

6. Carson HL, Templeton AR: Genetic Revolutions in Relation to Speciation Phenomena the Founding of New Populations. Annual Review of Ecology and Systematics 1984, 15:97-132.

7. Hoffman EA, Schueler FW, Jones AG, Blouin MS: An analysis of selection on a colour polymorphism in the northern leopard frog. Molecular Ecology 2006, 15:2627-2641

8. OHara RB: Comparing the effects of genetic drift and fluctuating selection on genotype frequency changes in the scarlet tiger moth. Proceedings of the Royal Society B-Biological Sciences 2006, 272:211-217.

9. Oxford G: Genetic drift within a protected polymorphism: Enigmatic variation in color-morph frequencies in the candy-stripe spider, Enoplognatha ovata. Evolution 2005, 59:2170-2184.

10. Armbruster $P$, Bradshaw WE, Holzapfel CM: Effects of postglacial range expansion on allozyme and quantitative genetic variation of the pitcherplant mosquito, Wyeomyia smithii. Evolution 1998, 52:1697-1704.

11. Uyeda JC, Arnold SJ, Hohenlohe PA, Mead LS: Drift Promotes Speciation by Sexual Selection. Evolution 2009, 63:583-594.

12. Lenormand T, Roze D, Rousset F: Stochasticity in evolution. Trends in Ecology \& Evolution 2009, 24:157-165.

13. Schluter D: The Ecology of Adaptive Radiation Oxford: Oxford University Press 2000.

14. Kingsolver JG, Hoekstra HE, Hoekstra JM, Berrigan D, Vignieri SN, Hill CE, et al: The strength of phenotypic selection in natural populations. American Naturalist 2001, 157:245-261.

15. Abbott J, Bensch S, Gosden T, Svensson El: Patterns of differentiation in a colour polymorphism and in neutral markers reveal rapid genetic changes in natural damselfly populations. Molecular Ecology 2008, 17:1597-1604.

16. Eroukhmanoff F, Hargeby A, Svensson El: Rapid adaptive divergence between ecotypes of an aquatic isopod inferred from F-ST-Q(ST) analysis. Molecular Ecology 2009, 18:4912-4923.

17. Christensen FB: Theories of Population Variation in Genes and Genomes Princeton: Princeton University Press 2008.

18. Losos JB, Jackman TR, Larson A, De Queiroz K, Rodriguez-Schettino L: Contingency and determinism in replicated adaptive radiations of island lizards. Science (Washington D C) 1998, 279:2115-2118.

19. Huey RB, Gilchrist GW, Carlson ML, Berrigan D, Serra L: Rapid evolution of a geographic cline in size in an introduced fly. Science (Washington D C) 2000, 287:308-309.

20. Langerhans R, Knouft JH, Losos JB: Shared and unique features of diversification in greater Antillean Anolis ecomorphs. Evolution 2006, 60:362-369.

21. Eroukhmanoff F, Hargeby A, Arnberg N, Hellgren O, Bensch S, Svensson El: Parallelism and historical contingency during rapid ecotype divergence in an isopod. Journal of Evolutionary Biology 2009, 22:1098-1110

22. Svensson E, Abbott J, Gosden TP, Coreau A: Female polymorphisms, sexual conflict and limits to speciation processes in animals. Evolutionary Ecology 2009, 23:93-108.

23. Gray SM, McKinnon JS: Linking color polymorphism maintenance and speciation. Trends in Ecology \& Evolution 2007, 22:71-79.

24. Roulin A: The evolution, maintenance and adaptive function of genetic colour polymorphism in birds. Biological Reviews (Cambridge) 2004 79:815-848.

25. Svensson El, Abbott J, Hardling R: Female polymorphism, frequency dependence, and rapid evolutionary dynamics in natural populations. American Naturalist 2005, 165:567-576.

26. Sinervo B, Lively CM: The rock-paper-scissors game and the evolution of alternative male strategies. Nature 1996, 380:240-243.

27. Sacchi R, Rubolini D, Gentilli A, Pupin F, Razzetti E, Scali S, et al: Morphspecific immunity in male Podarcis muralis. Amphibia-Reptilia 2007, 28:408-412.

28. Svensson E, Sinervo B, Comendant T: Density-dependent competition and selection on immune function in genetic lizard morphs. Proceedings of the National Academy of Sciences of the United States of America 2001, 98:12561-12565.
29. Sinervo B, Svensson E: Correlational selection and the evolution of genomic architecture. Heredity 2002, 89:329-338.

30. Sinervo B, Svensson E, Comendant T: Density cycles and an offspring quantity and quality game driven by natural selection. Nature 2000 406:985-988.

31. Sinervo B, Chaine A, Clobertt J, Calsbeek R, Hazard L, Lancaster L, et al: Selfrecognition, color signals, and cycles of greenbeard mutualism and altruism. Proceedings of the National Academy of Sciences of the United States of America 2006, 103:7372-7377.

32. Sinervo B, Bleay C, Adamopoulou C: Social causes of correlational selection and the resolution of a heritable throat color polymorphism in a lizard. Evolution 2001, 55:2040-2052.

33. Olsson M, Healey M, Wapstra E, Schwartz T, Lebas N, Uller T: Mating system variation and morph fluctuations in a polymorphic lizard. Molecular Ecology 2007, 16:5307-5315

34. Calsbeek R, Bonvini LA, Cox RM: Geographic variation, frequencydependent selection, and the maintenance of a female-limited polymorphism. Evolution 2009, 64:116-125.

35. Cote J, Le Galliard J, Rossi J, Fitze P: Environmentally induced changes in carotenoid-based coloration of female lizards: a comment on Vercken et al. Journal of Evolutionary Biology 2008, 21:1165-1172.

36. Vercken $E$, Sinervo B, Clobert J: Colour variation in female common lizards: why we should speak of morphs, a reply to Cote et al. Journal of Evolutionary Biology 2008, 21:1160-1164.

37. Pigliucci M: Phenotypic plasticity: beyond nature and nurture Baltimore, MD: John Hopkins University Press 2001

38. Seehausen O, Schluter D: Male-male competition and nuptial-colour displacement as a diversifying force in Lake Victoria cichlid fishes. Proceedings of the Royal Society Biological Sciences Series B 2004, 271:1345-1353.

39. Hughes KA, Du L, Rodd F, Reznick DN: Familiarity leads to female mate preference for novel males in the guppy, Poecilia reticulata. Animal Behaviour 1999, 58:907-916

40. Eakley AL, Houde AE: Possible role of female discrimination against 'redundant' males in the evolution of colour pattern polymorphism in guppies. Proceedings of the Royal Society Biological Sciences Series B 2004, 271:S299-S301

41. Kokko H, Jennions MD, Houde A: Evolution of frequency-dependent mate choice: keeping up with fashion trends. Proceedings of the Royal Society Biological Sciences Series B 2007, 274:1317-1324.

42. Schaeffer SW: Selection in Heterogeneous Environments Maintains the Gene Arrangement Polymorphism of Drosophila Pseudoobscura. Evolution 2008, 62:3082-3099.

43. Chunco AJ, McKinnon JS, Servedio MR: Microhabitat variation and sexual selection can maintain male color polymorphisms. Evolution 2007, 61:2504-2515.

44. Beaumont MA, Nichols RA: Evaluating loci for use in the genetic analysis of population structure. Proceedings of the Royal Society of London Series $B$ Biological Sciences 1996, 263:1619-1626.

45. Whitlock MC: Evolutionary inference from Q(ST). Molecular Ecology 2008, 17:1885-1896.

46. Corl A, Davis A, Kuchta SR, Sinervo B: Selective loss of polymorphic mating types is associated with rapid phenotypic evolution during morphic speciation. Proceedings of the National Academy of Sciences of the United States of America 2009.

47. West-Eberhard MJ: Alternative Adaptations Speciation and Phylogeny A Review. Proceedings of the National Academy of Sciences of the United States of America 1986, 83:1388-1392.

48. Arnold NE, Ovenden DW: A field quide to the reptiles and amphibians of Britain and Europe London: HarperCollins Publishers, 22002.

49. Cheylan M: Phenotypic Variation in Insular Populations of the Wall Lizard Podarcis muralis Off the French Mediterranean Coast. Revue d'Ecologie la Terre et la Vie 1988, 43:287-322.

50. Pafilis P, Meiri S, Fofopoulos J, Valakos E: Intraspecific competition and high food availability are associated with insular gigantism in a lizard. Naturwissenschaften 2009, 96:1107-1113.

51. Poulakakis N, Lymberakis $P$, Valakos E, Zouros E, Mylonas M: Phylogenetic relationships and biogeography of Podarcis species from the Balkan Peninsula, by Bayesian and maximum likelihood analyses of mitochondrial DNA sequences. Molecular Phylogenetics and Evolution 2005, 37:845-857. 
52. Perissoratis $\mathrm{C}$, Conispoliatis $\mathrm{N}$ : The impacts of sea-level changes during latest Pleistocene and Holocene times on the morphology of the Ionian and Aegean seas (SE Alpine Europe). Marine Geology 2003, 196:145-156.

53. Dermitzakis MD, Papanikolaou DJ: Paleogeography and geodynamics of the Aegean region during the neogene. Annales geologiques des pays helleniques 1981, 4:245-266.

54. Perez-Mellado V, Corti C, Cascio P: Tail autotomy and extinction in Mediterranean lizards. A preliminary study of continental and insular populations. Journal of Zoology (London) 1997, 243:533-541.

55. Snogerup S, Snogerup B: Changes in the flora of some Aegean islets 1968-2000. Plant Systematics and Evolution 2004, 245:169-213.

56. Reichardt TA, Bisson SE, Crocker RW, Kulp TJ: Analysis of flow-cytometer scattering and fluorescence data to identify particle mixtures. Proceedings of SPIE 2008, 6945, 69450R-69450R-8.

57. Bro R: Multi-way Analysis in the Food Industry Models, Algorithms and Applications. PhD Universiteit van Amsterdam 1998.

58. Statsoft Inc: STATISTICA (data analysis software system) Vers. 7 Tulsa, OK, USA: Statsoft Inc 2004.

59. Sambrook J, Fritsch EF, Maniatis T: Molecular Cloning: a Laboratory Manual Cold Spring Harbor Laboratory Press, 21989.

60. Wellenreuther M, Runemark A, Svensson E, Hansson B: Isolation and characterization of polymorphic microsatellite loci for the Skyros wall lizard Podarcis gaigeae (Squamata: Lacertidae). Molecular Ecology Resources 2009, 9:1005-1008.

61. Runemark A, Gabirot M, Bensch S, Svensson El, Martin J, Pafilis P, et al: Cross-species testing of 27 pre-existing microsatellites in Podarcis gaigeae and Podarcis hispanica (Squamata: Lacertidae). Molecular Ecology Resources 2008, 8:1367-1370.

62. Goudet J: FSTAT, A Program to Estimate and Test Gene Diversities and Fixation Indices. Version 2.9.3 2001 [http://www.unil.ch/popgen/softwares/ fstat.htm].

63. Pritchard JK, Stephens M, Donnelly P: Inference of population structure using multilocus genotype data. Genetics 2000, 155:945-959.

64. Evanno G, Regnaut S, Goudet J: Detecting the number of clusters of individuals using the software STRUCTURE: a simulation study. Molecular Ecology 2005, 14:2611-2620.

65. Waples RS, Do C: LDNE: a program for estimating effective population size from data on linkage disequilibrium. Molecular Ecology Resources 2008, 8:753-756.

66. Excoffier L, Laval G, Schneider S: Arlequin ver. 3.0:An integrated software package for population genetics data analysis. Evolutionary Bioinformatics Online 2005, 1:47-50.

67. Raymond M, Rousset F: GENEPOP (Version 1.2): Population genetics software for exact tests and ecumenicism. Journal of Heredity 1995, 86:248-249.

68. Simon JL: RESAMPLING STATS Arlington, Virginia: Resampling Stats Inc 2000

69. Coyne JA, Barton NH, Turelli M: Perspective: A critique of Sewall Wright's shifting balance theory of evaluation. Evolution 1997, 51:643-671.

70. Gillespie JH: Oxford Series In Ecology and Evolution The Causes of Molecular Evolution New York: Oxford University Press Inc 1991.

71. Corl A, Davis AR, Kuchta SR, Comendant T, Sinervo B: Alternative mating strategies and the evolution of sexual size dimorphism in the side blotched lizard Uta stansburiana: a population-level comparative analysis. Evolution 2009, 64:79-86.

72. Lande R: Models of Speciation by Sexual Selection on Polygenic Traits. Proceedings of the National Academy of Sciences of the United States of America-Biological Sciences 1981, 78:3721-3725.

73. Svensson E, McAdam AG, Sinervo B: Intralocus sexual conflict over immune defense, gender load, and sex specific signaling in a natural lizard population. Evolution 2009, 63:3124-3135.

74. Mayr E: Change of genetic environment and evolution. In Evolution as a Process. Edited by: Huxley J. London: Allen and Unwin; 1954:157-180.

75. Price T: Speciation in birds Greenwood Village, Colorado: Roberts\&Company Publishers 2007.

76. Wang IJ, Shaffer HB: Rapid color evolution in an aposematic species: phylogenetic analysis of color variation in the strikingly polymorphic strawberry poison-dart frog. Evolution 2008, 62:2742-2759.

77. Golding B: The Prospects for Polymorphisms Shared Between Species. Heredity 1992, 68:263-276.

78. Richman A: Evolution of balanced genetic polymorphism. Molecular Ecology 2000, 9:1953-1963.
79. Nei M, Li W-H: Probability of Identical Monomorphism in Related Species. Genetical Research 1975, 26:31-43.

80. Husband BC, Barrett SC: Effective population size and genetic drift in tristylous Eichhornia paniculata (Pontederiaceae). Evolution 1992, 46:1875-1890.

81. Beaumont MA, Balding DJ: Identifying adaptive genetic divergence among populations from genome scans. Molecular Ecology 2004, 13:969-980.

82. Manier M, Seyler C, Arnold S: Adaptive divergence within and between ecotypes of the terrestrial garter snake, Thamnophis elegans, assessed with F-ST-Q(ST) comparisons. Journal of Evolutionary Biology 2007, 20:1705-1719.

83. Wong A, Smith ML, Forbes MR: Differentiation between subpopulations of a polychromatic damselfly with respect to morph frequencies, but not neutral genetic markers. Molecular Ecology 2003, 12:3505-3513.

84. Merila J, Crnokrak P: Comparison of genetic differentiation at marker loci and quantitative traits. Journal of Evolutionary Biology 2001, 14:892-903.

85. Sinervo B, Miles DB, Frankino WA, Klukowski M, DeNardo DF: Testosterone, endurance, and darwinian fitness: Natural and sexual selection on the physiological bases of alternative male behaviors in side-blotched lizards. Hormones and Behavior 2000, 38:222-233.

86. Barrett RD, Schluter D: Adaptation from standing genetic variation. Trends in Ecology \& Evolution 2008, 23:38-44.

87. Rice A, Pfennig D: Character displacement: in situ evolution of novel phenotypes or sorting of pre-existing variation? Journal of Evolutionary Biology 2007, 20:448-459.

88. Seehausen O, Witte F, van Alphen J, Bouton N: Direct mate choice maintains diversity among sympatric cichlids in Lake Victoria. Journal of Fish Biology 1998, 53:37-55.

89. Savolainen R, Vepsalainen K: Sympatric speciation through intraspecific social parasitism. Proceedings of the National Academy of Sciences of the United States of America 2003, 100:7169-7174.

90. Lymberakis P, Poulakakis N, Kaliontzopotilou A, Valakos E, Mylonas M: Two new species of Podarcis (Squamata; Lacertidae) from Greece. Systematics and Biodiversity 2008, 6:307-318.

91. McKay JK, Latta RG: Adaptive population divergence: Markers, QTL and traits. Trends Ecol Evol 2002, 17:285-291.

doi:10.1186/1471-2148-10-269

Cite this article as: Runemark et al:: Island biology and morphological divergence of the Skyros wall lizard Podarcis gaigeae: a combined role for local selection and genetic drift on color morph frequency divergence?. BMC Evolutionary Biology 2010 10:269.

\section{Submit your next manuscript to BioMed Central and take full advantage of:}

- Convenient online submission

- Thorough peer review

- No space constraints or color figure charges

- Immediate publication on acceptance

- Inclusion in PubMed, CAS, Scopus and Google Scholar

- Research which is freely available for redistribution

Submit your manuscript at www.biomedcentral.com/submit
Biomed Central 